Brit. J. industr. Med., 1950, 7, 65.

\title{
CHRONIC INTOXICATION BY ETHYLENE GLYCOL VAPOUR*
}

\author{
BY \\ F. M. TROISI \\ Bologna, Italy \\ (RECEIVED FOR PUBLICATION JANUARY 16, 1950)
}

The industrial use of solvents continues to increase and leads to new observations in the technical and the pathological fields which call for the examination of new problems of industrial hygiene. In this paper attention is drawn to toxic manifestations of occupational origin recently observed and referable to the solvent ethylene glycol. This compound has in recent years found more numerous and more extensive industrial applications and evidence of its toxicity has been obtained both in human toxicology and by experiment.

\section{Ethylene Glycol}

Ethylene glycol $\left(\mathrm{CH}_{2} \mathrm{OH}-\mathrm{CH}_{2} \mathrm{OH}\right)$ is a colourless, odourless, somewhat viscous, sweetish liquid which boils at $197.2^{\circ} \mathrm{C}$, and solidifies at $-12.3^{\circ} \mathrm{C}$. Its specific gravity is 1.1176 at $15^{\circ} \mathrm{C}$.; its vapour tension is $0.09 \mathrm{~mm}$. $\mathrm{Hg}$ and it is miscible in all proportions with water and with alcohol. It is not inflammable. Its formula places it between the monohydric ethyl alcohol and the trihydric alcohol, glycerol, and in certain ways it resembles both these substances. It is the first and simplest of the glycol series and is extensively used as a solvent substitute for glycerol.

The principal industrial applications of ethylene glycol are as an electrolyte for electrolytic condensers ; a component in skin lotions in which it is physically mixed with various powders; an antifreeze agent ; a solvent for dyes ; and a vehicle in pharmaceutical preparations and food extracts.

It has been shown that ethylene glycol is rapidly absorbed from the gastro-intestinal tract and from subcutaneous tissues. It is oxidized to some extent in the body to oxalic acid, which increases the normal excretion of oxalates and produces more or less serious renal lesions. It has a narcotic action, slight however, in comparison with that possessed by monohydric alcohol. Toxic effects arising from the inhalation of its vapours are not possible at

\footnotetext{
- Translated into English by Maurice W. Goldblatt.
}

B normal temperatures because of its low volatility, and no such effects have in fact been reported. It is thus the more important from the industrial medical point of view that toxic effects have now been observed among industrial workers who were exposed to the inhalation of vapours produced by submitting ethylene glycol to high temperatures.

\section{Review of the Literature}

An examination of the pathological and toxicological literature especially of recent years reveals various cases of intoxication following oral ingestion of ethylene glycol and of protracted inhalation of the vapours of different glycols. These cases show the toxic action on the kidneys as well as a characteristic toxic effect on the central nervous system and on the blood-forming organs. It will be of interest to review these cases for comparison with the toxic manifestations I have observed.

Hansen (1930) described two cases of severe intoxication in two young men following accidental ingestion of a considerable quantity of ethylene glycol. This resulted from mistaking an ethylene glycol anti-freeze preparation for an alcoholic liquor. The two men a couple of hours after the ingestion showed severe signs of poisoning including stupor, somnolence, coma, complete bilateral paralysis of the abducent nerve accompanied by mydriasis and unreactive pupils. Death was prevented probably as a result of the decapsulation of one kidney in which hæmorrhagic nephritis was found.

Browning (1937) cites two cases of fatal poisoning brought about by the same accidental cause and in which toxic symptoms consisted of vomiting, cyanosis, and very severe prostration, death supervening by respiratory paralysis with convulsions.

In the 1944 annual report of the Chief Inspector of Factories, Merewether mentions a workman, 39 years of age, who died $21 \frac{1}{2}$ hours after having accidentally drunk $140 \mathrm{gm}$. of ethylene glycol mixed with a small quantity of anti-corrosive. The 
symptoms in this case resembled a severe alcoholic intoxication. In the report of the previous year two cases of poisoning are recorded as due to the same sort of accident. A similar accident in 1946 brought about a fatal intoxication from ethylene glycol in an Italian boy, the cause of death being toxic nephritis.

Among workers in English factories who had been in contact with ethylene glycol no definite symptoms of intoxication were found, and only two of them complained; one, engaged on the work for two years, complained of slight conjunctival irritation and rhinitis, and the other, after nine months, complained of loss of appetite and slight mental torpor (Browning, 1937).

Widman (1946) reported six cases of acute occupational poisoning leading to death with severe renal lesions from thirty hours to six days after the absorption of ethylene glycol. Two of the cases showed acute anæmia with complete anuria, and at the necropsy severe tubular lesions were found and numerous crystals of calcium oxalate, especially in the renal cortex.

Opsahl (1948) published a paper recording the mass poisoning of 67 people brought about by an anti-freeze solution consisting of methyl alcohol (10 per cent.) and of ethylene glycol (90 per cent.). In two cases the poisoning was fatal ; in one it led to complete blindness and in another it led to severe disturbances in vision. The remaining cases recovered.

Hagemann and Chiffelle (1948) investigated three men who had drunk a liquid containing 40 per cent. of ethylene glycol and developed a fatal syndrome of coma, acidosis, hypertension, and convulsions. They also found marked leucocytosis, albuminuria, microscopic hæmaturia, raised N.P.N. in the blood, changes in the C.S.F. and, anatomically, hæmorrhages in the lungs, kidneys, brain, and myocardium, and fatty infiltration of the liver and changes in the brain and meninges indicative of a toxic meningoencephalitis.

Zehrer (1948) described three cases of poisoning (one fatal) which resulted from ingestion of ethylene glycol sold as glycerol. Presenting symptoms were malaise, nausea, vertigo, pallor, cold sweats, paraesthesia of the extremities, fluttering pulse, somnolence, and then profound coma with abolition of reflexes. On awakening, the survivors showed retrograde amnesia and lateral nystagmus. There was no anuria but only signs of involvement of the central nervous system.

Much laboratory work on animals (oral, subcutaneous, intramuscular, intravenous, and intraperitoneal administration) has pointed to a depressant action of ethylene glycol on the central nervous system (Hanzlik and others, 1931 ; von Oettingen and Jirouch, 1931); a selective toxic effect on the kidneys, with severe lesions and marked oxaluria of renal origin, and disturbance of lipoid metabolism, attributed to dysfunction of the liver and kidneys (Mauro, 1939).

Several derivatives of ethylene glycol, with the characters of ethers or esters, have in recent years acquired considerable importance as industrial solvents. Inhalation of the vapours of these derivatives has given rise to toxic effects. Donley (1936) reported a case of toxic encephalopathy in a woman engaged in ironing shirt collars treated with a solvent designed to render them stiff. This solvent contained 3 per cent. of methyl cellosolve $\left(\mathrm{OHCH}_{2}-\mathrm{CH}_{2} \mathrm{O}-\mathrm{CH}_{3}\right)$ which volatilized during the hot ironing. Besides the cerebral symptoms the woman presented an anæmia with lymphocytosis (R.B.C. 3,500,000 ; Hb 85 per cent. ; lymphocytes 46 per cent.). Greenburg and others (1938) gives clearer toxic pictures in 19 young women who had been engaged in the same kind of work but in which the solvent used contained 33 per cent. methyl cellosolve. Of these, two became ill with the acute form of aplastic anæmia with tremors and marked psychic depression ; one showed polyneuritis with neurological sequelæ, whilst the remaining 16 cases all showed abnormal blood pictures. Among these last there were four with abnormal reflexes and tremors of the hands, and four with both these symptoms in more marked degree as well as signs of somnolence and lassitude. The blood pictures indicated forms of macrocytic anæmia with reduction of platelets and the appearance of young granulocytes.

Severe poisoning has also been produced by the inhalation of the vapour of diethylene dioxide or dioxan, the cyclic ether of ethylene glycol. Barber (1934) reported five fatal cases of an acute form of intoxication lasting five to eight days in workers who had been exposed for 15 days to high concentrations of dioxan vapour. During this period the workmen experienced pain in the nose and eyes, migrainous headache, somnolence, vertigo, loss of appetite and nausea and finally presented a syndrome characterized by grave gastric symptoms, enlarged liver without jaundice, anuria, and uræmic coma. Necropsy of four out of the five cases gave evidence of hæmorrhagic nephritis and hepatic necrosis.

It is seen, therefore, that the toxic action of the glycols is directed particularly to the nervous system and the blood-forming organs in the case of the inhalation of vapours, whilst when administered by mouth or by parenteral routes the action is more directed to the kidneys. The three cases of Zehrer in which ethylene glycol was ingested are excep- 
tional inasmuch as the toxicological picture included signs of definite involvement of the central nervous system.

\section{Observations in an Electrolytic Condenser Factory}

My observations presented on the toxic effects of the inhalation of ethylene glycol vapour were made on women workers engaged in a department of a factory where electrolytic condensers were made. These condensers are constructed from an outer case of aluminium, in which is contained a cylindrical element formed by a positive armature and a negative made from aluminium ribbon, separated by a paper ribbon impregnated with the electrolytic mixture and rolled together. One phase of the work involved spreading a mixture of 40 per cent. ethylene glycol, 55 per cent. boric acid, and 5 per cent. ammonia, constituting the electrolyte of the condenser, on a strip of paper placed on another strip of aluminium, whereby it was absorbed by the paper. This operation was carried out by hand with paint brushes by about 40 women seated at long tables. The mixture was contained in receptacles placed at such a distance from the workers, in the middle of the tables, that it was readily reached by the outstretched hand. These receptacles were maintained, by electric heaters, at $105^{\circ} \mathrm{C}$., this temperature being necessary to keep the mixture fluid : at room temperature the mixture solidifies.

The work was done in a spacious large room amply provided with openings, fairly well lighted and ventilated, but the workwomen were nevertheless exposed to the vapours of ethylene glycol which they constantly inhaled. Whilst at ordinary temperatures ethylene glycol gives off practically no vapour, in this work the evolution of vapours was continuous and always within inhaling distance of the women, the receptacles containing the hot fluid being quite close to them during the spreading operation. For the purposes of this process it was necessary that the ethylene glycol should be of the highest purity.

All the women were young and the majority of them had been already engaged on the work for a couple of years.

For some time several of these women, with greater or less frequency, had been subject to attacks of loss of consciousness without having ever suspected their work as the cause of them, but attributing them to some common nervous disturbance. It was found that whilst the women were intent on their work one or other of them without warning would suddenly emit a cry as if a prey to sudden and quickly passing agitation and would pass into a state of profound sleep. Taken at once to the works surgery the loss of consciousness was seen to last for only 5 or 10 minutes and was followed by rapid awakening without amnesia and with such a quick return to normality that the patients demanded to return to their work. The period of sleep appeared to be calm and tranquil and was not followed by any return of any particular symptoms. These attacks increased in frequency during the summer and recurred as a rule after a few hours of continuous work, about 11 o'clock in the morning shift and in the first hour or so in the afternoon after lunch. These two facts were evidently connected with the possibility of a large absorption of the vapour of ethylene glycol.

Of the 38 women engaged in this work, nine were subject to attacks which recurred rather frequently, and on the average two or three times a week, but in a few cases almost every day. These latter on clinical examination showed signs of well-defined nystagmus. Five of these women (those who most frequently developed the attacks) were subjected to the thermal test of Barany without provoking abnormal reactive movements and vertigo, and on hæmatological examination they showed absolute lymphocytosis in every case.

Examination of the urine in the whole group showed no abnormality. It was not possible to carry out examinations of the blood and urine of all the 38 women employed in the department, so that the remaining 29 women, never having had the attacks described, were examined clinically as ambulatory subjects : it was thus found that five of them showed nystagmus but no other signs.

In Table I the relevant data are given on the nystagmus observed and on the hæmatological findings. Cases 1 to 9 had attacks of unconsciousness. Cases 10 to 14 had no attacks of unconsciousness.

Of the nine workers having attacks of unconsciousness, only two, who experienced them rather frequently, were removed from the department and transferred to alternative work. In the new work the attacks no longer occurred. The remaining seven women elected to stay at the job because they were told that it had been decided to instal a plant which would mechanize and enclose the process and by internal draughting of the vapours of the ethylene glycol permit of its recovery. Since the installation of this plant there has been no change in the state of health of the women employed, excluding the two transferred, and there have been no further attacks of unconsciousness or nystagmus. On the other hand, before the mechanization of the process, when it was still carried out by hand, and up to eight months from the first examination, there were still attacks of unconsciousness and nystagmus could still be verified among the women remaining in the department. 
TABLE I

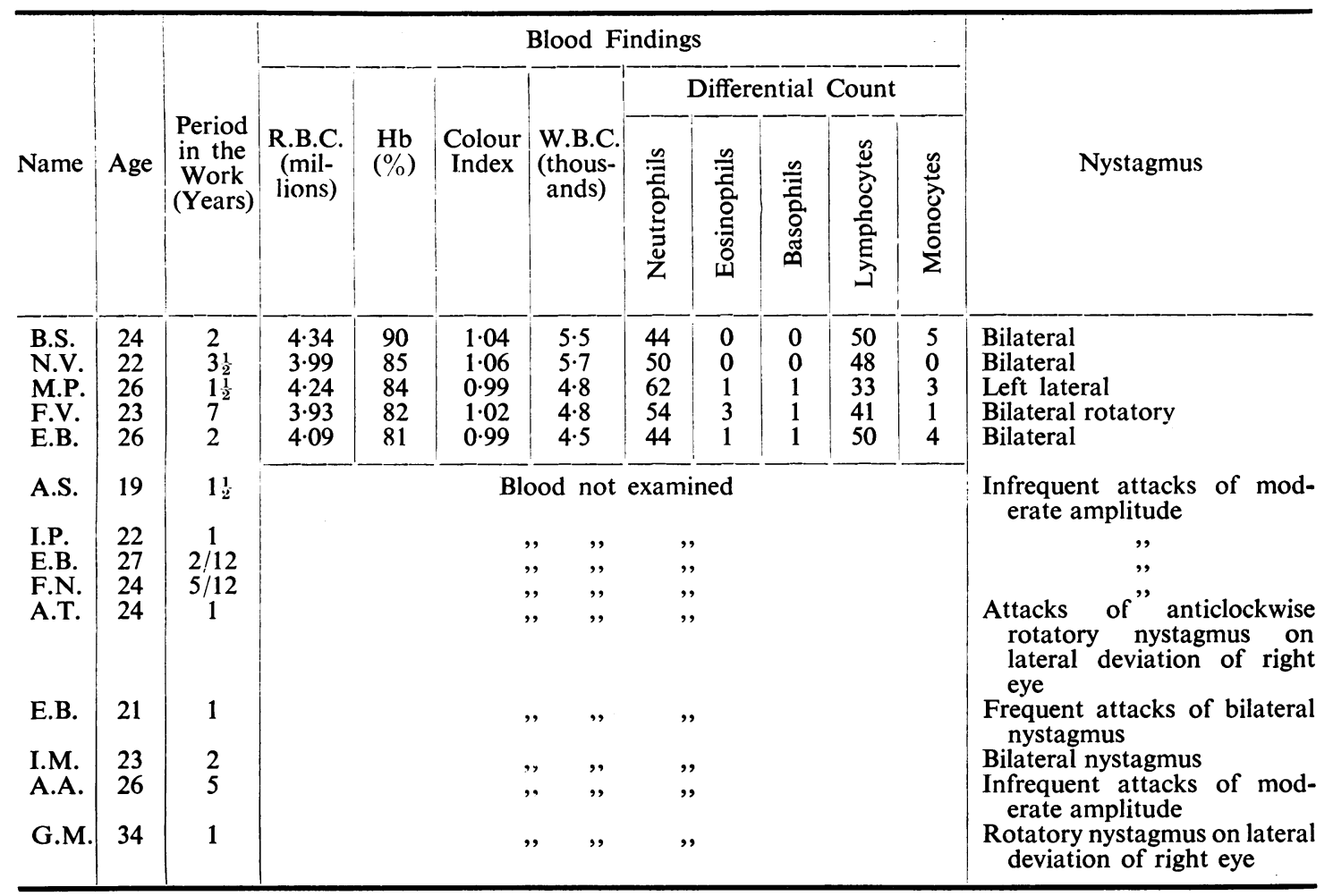

\section{Discussion}

The following facts indicate the ætiological significance of the inhalation of the vapours of ethylene glycol in producing toxic effects. (1) Cessation of the attacks after enclosure and draughting of the process ; (2) cessation of the attacks among the two workers transferred to alternative work; (3) absence of such attacks among workers in other parts of the same factory where women are employed and where vapours and fumes are evolved. (The factory strength consists of about 1,500 women, mostly young.) These facts negative any suggestion that the attacks were of a hysterical nature. There was no indication of any kind that either ammonia, ( 5 per cent. of the mixture) or boric acid ( 55 per cent. of the mixture) could have had anything to do with the toxic effects observed.

The nystagmus could not be referred to strain caused by the visual apparatus because the excellent environmental lighting was by direct sunlight and the work did not involve any fatigue of the eye muscles, the visual excursion in the spreading operation being limited to no more than $50 \mathrm{~cm}$.

The type of nystagmus met with, although in most cases horizontal and suggesting the possibility of a peripheral lesion of the vestibular apparatus, was in two cases unequivocally rotatory in character. This fact led us to the more probable view that the lesion was nuclear for, although rotatory nystagmus occurs in lesions of both semicircular canals and cases have been described in lesions of only one canal, it is difficult to imagine a toxic agent selectively attacking one or both semicircular canals. The latter hypothesis is indeed invalidated by the accompanying periodic attacks of unconsciousness which must be a consequence of toxic effects on the brain, and by the fact that nystagmus occurred, unaccompanied by abnormalities of reactive movements or by vertigo, in five workers, who were most subject to attacks, after excitation by means of Barany's thermal test. These considerations could lead us to interpret such cases of nystagmus as of supranuclear origin and without participation of the vestibular nuclei. There is, of course, no question in these cases of either congenital or hysterical nystagmus.

The absolute lymphocytosis found in all the five cases in which blood counts were made (Table I) reveals a quite distinct pathological action on hæmatopoiesis, even taking into account the normal 
variations in the relative proportions of lymphocytes in the blood and also of the fact that bad technique could give rise to variations of this magnitude.

The references quoted from the literature reinforce the conclusions we have given as to the ætiology of the toxic effects. These all point to the inhalation of the vapour of ethylene glycol as causing periodic loss of consciousness, nystagmus, and lymphocytosis. The limited character of the effects produced was a consequence of the limited extent of possible absorption by inhalation of the vapour of this substance.

Whilst loss of consciousness and nystagmus went together in many cases, the fact that some cases showed nystagmus but no attacks of unconsciousness may perhaps be explained by some greater resistance to the toxic action in some individuals. This leads to the hypothesis that nystagmus may be regarded as an early sign and precursor of more severe intoxication in view of the fact that the majority of authors regard the nuclear and supranuclear centres to be more sensitive and more likely to react to toxic influences.

Nystagmus was also present in the three cases reported by Zehrer (1948). Nystagmus of a type similar to that described in the present paper figures in reports on poisoning by phenyl-hydroxylamine, an aromatic amine easily absorbed through the skin and producing cyanosis, depression of the central nervous system, spasms, trismus, nystagmus, and disturbances of the respiration and circulation (von Oettingen and Sayers, 1931, quoted by Lanza and Goldberg, 1939).

It is recommended that systematic examination for nystagmus should be practised for workers in contact with glycols or other solvents of the fatty or the aromatic series.
Summary

In an electrolytic condenser factory, 38 women were engaged in spreading on paper and aluminium strips a mixture of 40 per cent. ethylene glycol, 55 per cent. boric acid and 5 per cent. ammonia, maintained at $105^{\circ} \mathrm{C}$. There was continuous evolution of the vapour of ethylene glycol to which the women were exposed by the method of operation.

In nine of these women there were frequent attacks of loss of consciousness and nystagmus was also observed. In five of these absolute lymphocytosis was found by blood examination.

A further five cases of nystagmus but without attacks of unconsciousness were discovered among the remaining workers.

The attacks completely disappeared when the process was operated in an enclosed plant permitting of recovery of the ethylene glycol, the personnel remaining unchanged. Removal of two severe cases to other work also led to complete cessation of attacks.

\section{REFERENCES}

Barber, H. (1934). Guy's Hospital Rep., 84, 267.

Browning, E. (1937). "Toxicity of Industrial Organic Solvents" Medical Research Council-Industrial Health Research Board, London, No. 80.

Donley, D. E. (1936). J. industr. Hyg., 18, 571.

Greenburg, L., Mayers, W. R., Goldwater, L. J., Burke, W. J., and Moskowitz, S. (1938). J. industr. Hyg. 20, 134

Hagemann, P. O., and Chiffelle, T. R. (1948). J. Lab. clin. Med. 33, 73 ; Bull. Hyg., Lond., 23, 872.

Hansen, H. (1930). "Sammlung für Vergiftungsfalle", Leipzig, 1, 175 .

Hanzlik, P. J., Seidenfeld, M. A., and Johnson, C. C. (1931). J. Pharmacol., 41, 387.

Lanza, A. J.. and Goldberg, J. A. (1939). "Industrial Hygiene". Oxford University Press, New York

Mauro, V. (1939). Folia med., Napoli, 25, 840.

Merewether, E. R. A. (1943, 1944). "Annual Report of the Chief Inspector of Factories", London.

Oettingen, W. F. von, and Jirouch, E. A. (1931). J. Pharmacol., 42, 355 .

Opsahl, R. (1948). Nord. med. scand., 39, 1431.

Widman, C. (1946). Acta med. scand., 126, 295.

Widman, C. (1946). Acta med. scand., 126, 